\title{
AVALIAÇÃO DE LUBRIFICANTES PARA ESTAMPAGEM UTILIZANDO O ENSAIO DE ESTAMPABILIDADE ERICHSEN*
}

\author{
Juliano Walter Silva ${ }^{1}$ \\ José Antônio Esmerio Mazzaferro ${ }^{2}$ \\ Cíntia Cristiane Petry Mazzaferro ${ }^{3}$
}

\begin{abstract}
Resumo
O rápido crescimento da indústria automotiva em meados de 1920 impulsionou de forma significativa o desenvolvimento dos processos de estampagem. Hoje, esse processo de fabricação está consolidado e abrange desde a produção de utensílios domésticos até a de componentes automotivos. O estudo realizado tem como objetivo comparar e mensurar a capacidade de lubrificação de três produtos lubrificantes que atuam durante o processo de estampagem. O material estampado foi uma folha de flandres convencional com quatro variações de acabamentos superficiais. O ensaio utilizado foi o ensaio de estampabilidade, o qual nos fornece como parâmetro final o índice de estampabilidade Erichsen (h). Pela comparação dos índices Erichsen de estampabilidade obtidos pôde-se estimar a eficiência de cada regime de lubrificação.
\end{abstract}

Palavras-chave: Lubrificante; Estampagem; Ensaio; Erichsen.

\section{EVALUATION OF LUBRICANTS FOR STAMPING USING THE ERICHSEN CUPPING TEST}

\section{Abstract}

The fast growth of the automotive industry in the mid-1920s boosted significantly the development of the stamping processes. Nowadays, this manufacturing process is consolidated and comprehend from the production of household appliances to automotive components. The objective of this study is to compare and measure the lubricating capacity of three lubricants during the stamping process. The stamped material was a conventional tinplate with four variations of surface finishing. The test used was the Erichsen cupping test which provides as the final parameter the Erichsen cupping index (h). Comparing the Erichsen cupping index obtained, was possible to estimate the efficiency of each lubricant system.

Keywords: Lubricant; Stamping; Erichsen; Cupping; Test.

1 Graduando de Engenharia Metalúrgica, LS\&TC/DEMEC/EE/UFRGS, Porto Alegre, RS/Brasil.

Engenheiro Mecânico, Prof. Dr., LS\&TC/DEMEC/EE/UFRGS, Porto Alegre, RS/Brasil.

Engenheira Metalúrgica, Prof. Dr., LS\&TC/DEMEC/EE/UFRGS, Porto Alegre, RS/Brasil. 


\section{INTRODUÇÃO}

A estampagem é um processo de conformação dos metais, no qual uma chapa é deformada plasticamente para se obter uma configuração final desejada. O fluxo de metal é influenciado prioritariamente pela geometria do punção, condição de lubrificação e as condições térmicas existentes na zona de deformação [1].

A formabilidade de chapas metálicas é a medida da habilidade de um material em submeter-se a forma final desejada sem que ocorra falhas. Assim, para uma completa avaliação da formabilidade existem testes diretos, como o Ensaio Erichsen. [1].

O estiramento é o processo de conformação que consiste na aplicação de forças de tração de maneira a esticar o material sobre uma ferramenta ou bloco-modelo. Em virtude da complexidade inerente aos processos de conformação de chapas metálicas, as medidas das propriedades mecânicas feias simplesmente a partir de ensaios de tração são de valor limitado. Vários ensaios de laboratório foram desenvolvidos através dos anos, com o intuito de avaliar a conformabilidade das chapas dos diversos materiais. O ensaio Swift é padronizado para o embutimento e nele a estampabilidade é expressa em termos da razão limite de estampagem. Nos teste Olsen e Erichsen a chapa é fixada entre dois aros metálicos enquanto que um punção, geralmente esférico, é pressionado contra a chapa até que esta se frature. O parâmetro medido é a profundidade do abaulamento que se forma na chapa antes da ruptura. Nestes testes a chapa é submetida principalmente a um estiramento, enquanto que no ensaio Swift ocorre praticamente embutimento puro. [2]. Como o objetivo do trabalho era avaliar a capacidade de lubrificação em processos de estiramento escolheu-se o ensaio de estampabilidade Erichsen.

O ensaio de estampabilidade Erichsen é um teste tecnológico que trabalha com uma matriz com abertura circular e um punção em forma de esfera. O ensaio possibilita julgar a aptidão do material para o uso em processos de estiramento. O resultado do teste é índice de estampabilidade Erichsen (h) que, geometricamente, é o deslocamento do punção do início até a ruptura parcial da chapa ensaiada. Para diminuir o atrito entre as superfícies do punção e da chapa, geralmente é usado um lubrificante [3]. Uma visão geral do ensaio é mostrada na Figura 1 [6].

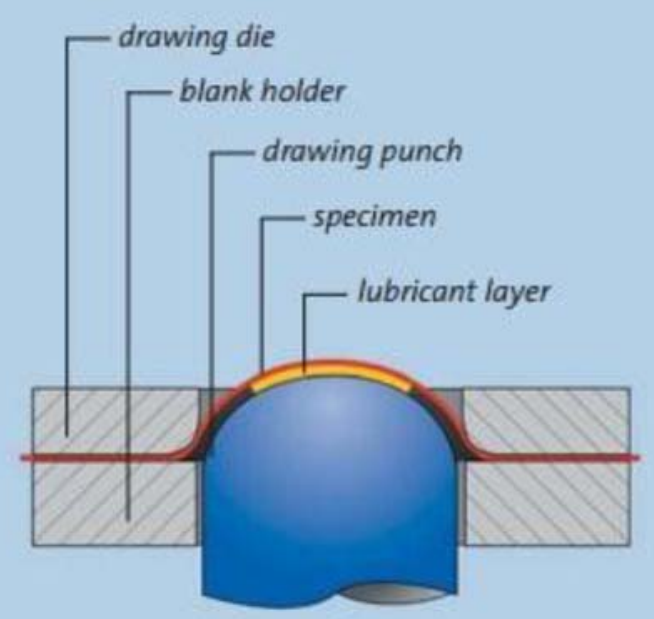

Figura 1. Representação esquemática (em corte) do Ensaio Erichsen, mostrando os elementos envolvidos. Fonte: ERICHSEN GmbH \& Co. KG 
No estiramento de chapas metálicas, a posição inicial da estricção depende da condição de atrito entre a interface peça-punção. Um regime de lubrificação adequado ameniza o efeito do atrito, aumenta a vida útil do ferramental e melhora o acabamento superficial da peça conformada. As condições de atrito entre o punção e a chapa são de grande influência no escoamento do material, na formação de defeitos internos e superficiais, nas tensões sofridas pelo material, na carga aplicada pelo punção e na energia requerida para o processo de conformação [1].

O sistema hidrodinâmico de lubrificação é aquele no qual um filme de lubrificante fica presente entre o punção e a chapa a ser conformada. Neste caso, as condições de atrito são governadas pela interação entre velocidade do punção e o filme lubrificante. Quando ocorre atrito seco, sem uso de lubrificante, a velocidade do punção é o fator que controla o regime de atrito.A viscosidade dos lubrificantes, em maioria, decresce rapidamente com a temperatura, logo deve-se realizar os ensaios com a mesma temperatura para evitar diferentes viscosidades e diferentes capacidades de lubrificação.

A motivação do presente trabalho surgiu pela necessidade de uma Empresa, que produz embalagens metálicas, em quantificar o quão cada lubrificante poderia facilitar a estampagem. O processo utilizado na indústria visa à fabricação do domo de uma lata aerossol, que sofre sete processos de estampagem em sequência, consequentemente o regime de lubrificação é um item de suma importância. Em uma parceria entre academia $e$ indústria sugerimos utilizar o ensaio de estampabilidade Erichsen para avaliar qual sistema de lubrificação forneceria o maior índice de estampabilidade Erichsen. No presente estudo, a lubrificação foi a principal variável a ser analisada e comparada em chapas (folhas de flandres) com variados tipos de acabamentos superficiais.

\section{MATERIAIS E MÉTODOS}

As matérias primas utilizadas para os testes foram chapas (folhas de flandres) com baixo teor de carbono $(<0,1 \% \mathrm{wt})$ e espessuras iguais de $0,30 \mathrm{~mm}$. Um esquema das camadas que compõem uma folha de flandres pode ser visto na Figura 2 [5]. 


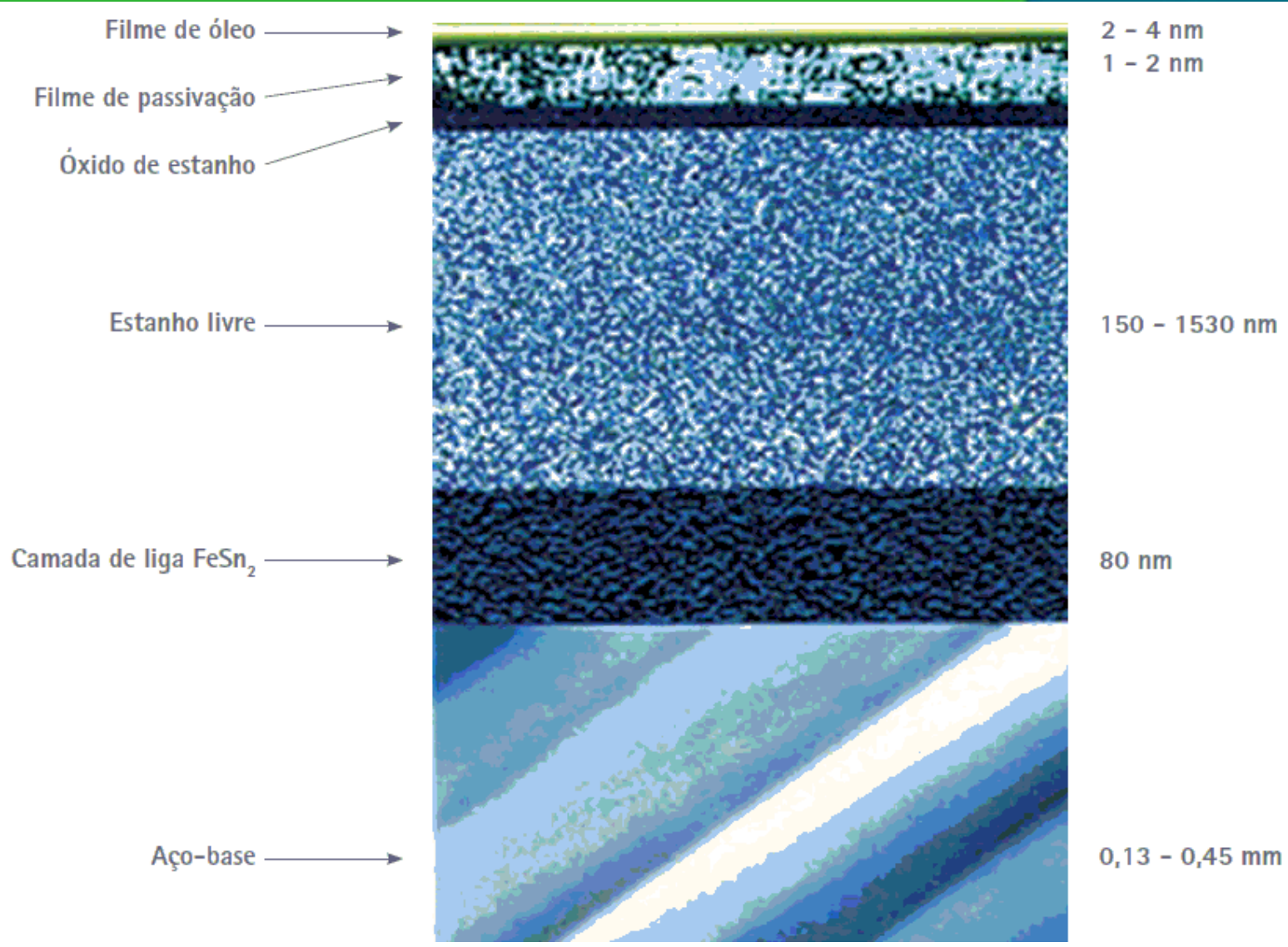

Figura 2. Camadas de materiais observados em uma folha-de-flandres (corte transversal). Fonte: Companhia Siderúrgica Nacional

Utilizou-se chapas com quatro diferentes acabamentos superficiais, e cada chapa foi ensaiada utilizando-se quatro condições distintas de lubrificação, como pode ser visto na Tabela 1. Nota-se nessa Tabela que os tipos de lubrificantes e acabamento superficial não têm suas características técnicas especificadas, por serem tratados como segredo industrial pela Empresa de embalagens. No entanto, pode se afirmar que são camadas finas e de mesma espessura de variados polímeros, um exemplo é o Polietileno Tereftalato (PET). A camada é aplicada entre o Filme de passivação e - Filme de óleo na Figura 2 Considera-se, como exemplo, na Tabela 1 que o Lubrificante $A$ foi ensaiado três vezes com a condição de acabamento 1, três vezes com a condição de acabamento dois, três vezes com a condição de acabamento 3 e três vezes com a condição de acabamento 4, totalizando doze ensaios com 0 lubrificante $A$. Os lubrificantes $B$ e $C$ foram ensaiados da mesma forma. A condição de não lubrificação teve um ensaio a menos em cada condição de acabamento, totalizando oito ensaios com tal condição. Vale ressaltar que para os cálculos seguintes foi usada avaliação estatística para os ensaios com três repetições. 
Tabela 1. Número de ensaios para cada parâmetro utilizado nos ensaios Erichsen.

\begin{tabular}{|c|c|c|c|c|}
\hline \multirow{2}{*}{$\begin{array}{c}\text { Condição de } \\
\text { acabamento }\end{array}$} & \multicolumn{4}{|c|}{ Número de ensaios } \\
\cline { 2 - 5 } & Lubrificante $\boldsymbol{A}$ & Lubrificante B & Lubrificante C & Sem Iubrificante \\
\hline $\mathbf{1}$ & 3 & 3 & 3 & 2 \\
\hline $\mathbf{2}$ & 3 & 3 & 3 & 2 \\
\hline 3 & 3 & 3 & 3 & 2 \\
\hline $\mathbf{4}$ & 3 & 3 & 3 & 2 \\
\hline
\end{tabular}

O equipamento utilizado para o ensaio de estampabilidade Erichsen foi a máquina universal de ensaios EMIC 23-600, mostrada na Figura 3., com as seguintes características:

- Capacidade: 60 toneladas

- Velocidade: até $300 \mathrm{~mm}$ por segundo

- Aquisição de dados embutida no próprio equipamento

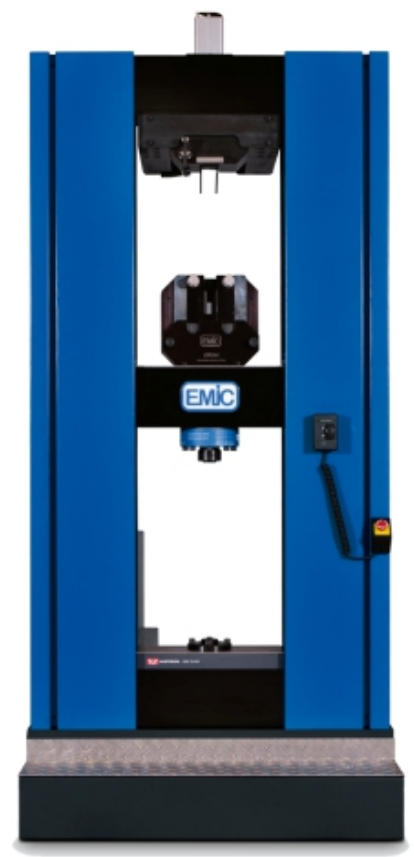

Figura 3. Máquina universal de ensaios EMIC 23-600 utilizada nos ensaios Erichsen.

As amostras tinham dimensões de $90 \mathrm{~mm} \times 90 \mathrm{~mm}$, e todas foram ensaiadas com velocidade de aplicação da carga de $5 \mathrm{~mm} / \mathrm{min}$ [4]. O ensaio era interrompido quando a carga aplicada caia em $20 \%$ aproximadamente, indicando que já havia ocorrido a fratura do material. 


\section{RESULTADOS E DISCUSSÃO}

Os valores (médios) de índice de estampabilidade de Erichsen (h) de cada experimento estão listados na Tabela 2, e a comparação deles pode ser vista no Gráfico 1.

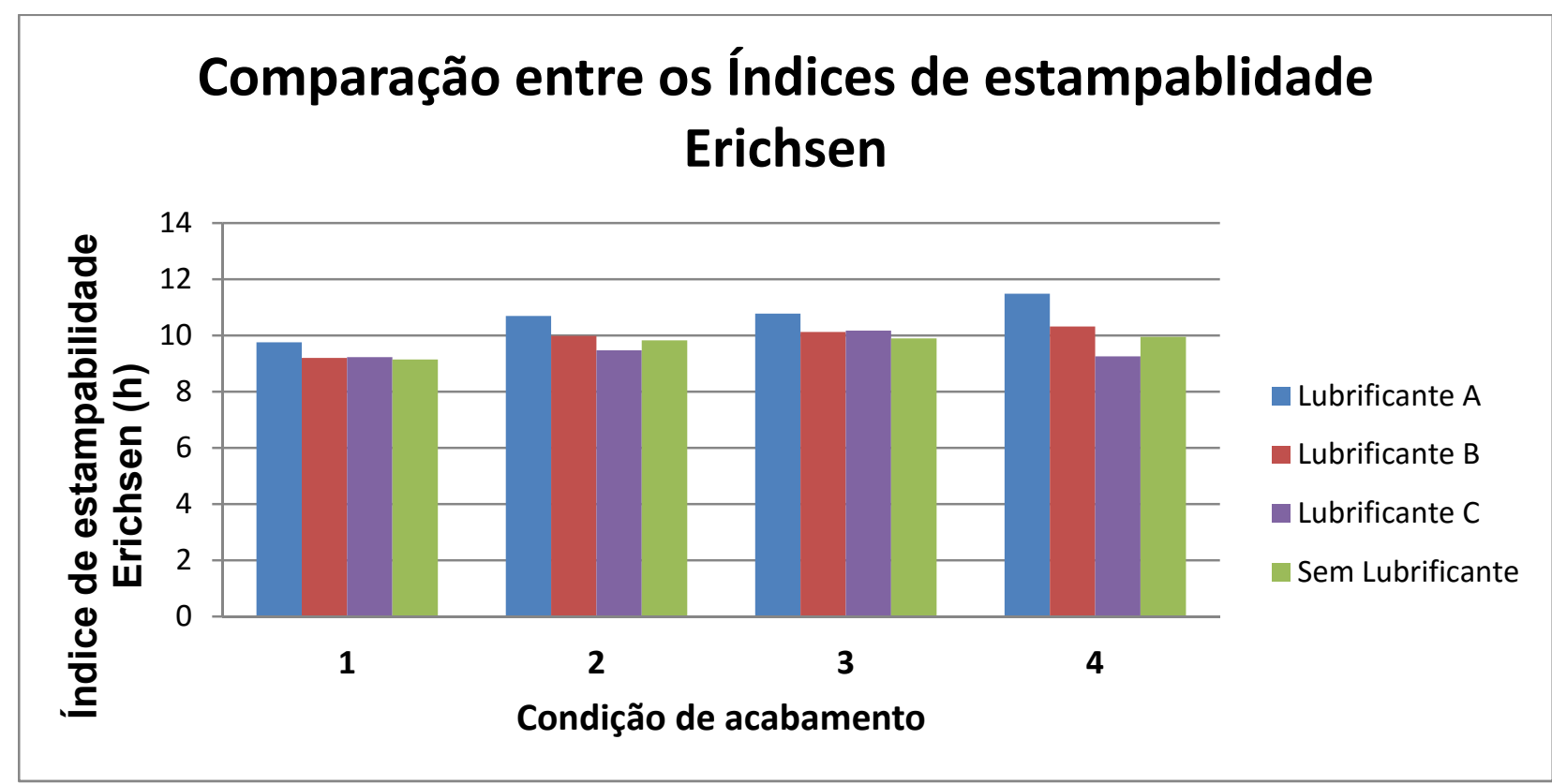

Gráfico 1. Comparação dos índices de estampabilidade Erichsen para as diferentes condições de acabamento.

A análise do gráfico permite fazer as seguintes considerações:

i) $O$ uso do lubrificante $A$ foi o que resultou em melhor desempenho em estampabilidade, para todas as condições de acabamento superficial testadas;

ii) Os lubrificantes A e B mostraram um comportamento de aumento progressivo do índice de estampabilidade conforme se varia o acabamento superficial, de 1 até 4. O lubrificante $A$ estampou, em relação ao $B, 5,74 \%$ a mais quando utilizado o acabamento $1,6,64 \%$ a mais quando utilizado o acabamento 2, $6,03 \%$ a mais quando empregado o acabamento 3 , e $10,18 \%$ a mais quando utilizado o acabamento 4 , ou seja, a chapa estampou em média $7,15 \%$ a mais quando utilizado o lubrificante $A$ em relação ao $B$;

iii) Um mesmo "padrão" de comportamento pode ser observado nos tipos de acabamento 1 e 3, assim como nos acabamentos 2 e 4 . Nessas duas últimas condições de acabamento, o melhor índice foi obtido com o uso do lubrificante $A$, seguido pelo $B$, pela não utilização de lubrificante $e$, por último, pelo lubrificante C. Quando utilizados os acabamentos 1 e 3, a utilização do lubrificante A ocasionou um maior índice de estampabilidade enquanto que, considerando os erros associados às medições, os valores de estampabilidade foram muito similares nas outras condições de lubrificação;

iv) Os resultados de formabilidade utilizando o lubrificante $\mathrm{C}$ foram insatisfatórios, pois com ele obteve-se resultados similares, ou mesmo piores, quando comparado com a não utilização de lubrificante.

Do ponto de vista da indústria, observa-se que, nos tipos de acabamento 1 e 3 , como os valores de índice de estampabilidade utilizando os lubrificantes $\mathrm{B}$ e $\mathrm{C}$, e também sem lubrificante, são muito similares, então considerando-se apenas os 
valores de estampabilidade, não valeria a pena utilizar esses lubrificantes, pois seria um gasto que à princípio não traria benefícios para a Empresa. Uma observação semelhante refere-se ao uso do lubrificante $\mathrm{C}$, pois os valores dos índices foram similares ou mesmo inferiores aos obtidos sem a utilização de lubrificante, considerando todos os tipos de acabamento empregados nesse estudo.

$\mathrm{Na}$ Tabela 2 pode-se verificar os valores (médios) dos índices de estampabilidade Erichsen (em milímetros) para cada condição ensaiada, assim como a amplitude (diferença entre o maior e menor valor, para cada tipo de acabamento, em milímetros) e o valor da amplitude em termos percentuais. A amplitude média em milímetros chegou a 1,06 e, em porcentagem, a 9,79; esses valores confirmam a importância em se utilizar um regime de lubrificação adequado nos processos de estampagem.

Tabela 2. Comparação entre as médias do índice de estampabilidade Erichsen e a amplitude.

\begin{tabular}{|c|c|c|c|c|c|c|}
\hline Cond. de acabamento & Lubrificante A $(\mathrm{mm})$ & Lubrificante B $(\mathrm{mm})$ & Lubrificante C (mm) & Sem Lubrificante $(\mathrm{mm})$ & Amplitude (mm) & Amplitude $(\%)$ \\
\hline 1 & 9,76 & 9,20 & 9,23 & 9,15 & 0,61 & 6,25 \\
\hline 2 & 10,69 & 9,99 & 9,48 & 9,83 & 1,22 & 11,38 \\
\hline 3 & 10,78 & 10,13 & 10,18 & 9,90 & 0,88 & 8,16 \\
\hline 4 & 11,49 & 10,32 & 9,26 & 9,95 & 1,54 & 13,38 \\
\hline
\end{tabular}

É importante salientar que o acabamento superficial final nos sistemas com lubrificação foi superior ao sistema não lubrificado, pois observou-se uma superfície muito mais opaca no topo da identação quando não foi utilizado nenhum lubrificante, como pode-se observar na Figura 4, ambas as superfícies foram limpas para a comparação visual. Quando utilizado algum sistema de lubrificação, essa região não ficou com um nível de opacidade tão elevado, como pode ser visto na Figura 5 . Isso pode ser atribuído à uma provável alteração das condições de atrito entre o punção e o material, com o uso de lubrificantes.

Essa observação, juntamente com as informações dos valores dos índices de estampabilidade, nos faz perceber que o uso de lubrificantes pode não apenas melhorar a estampabilidade de um material, mas também melhorar o acabamento superficial final do estampado. 


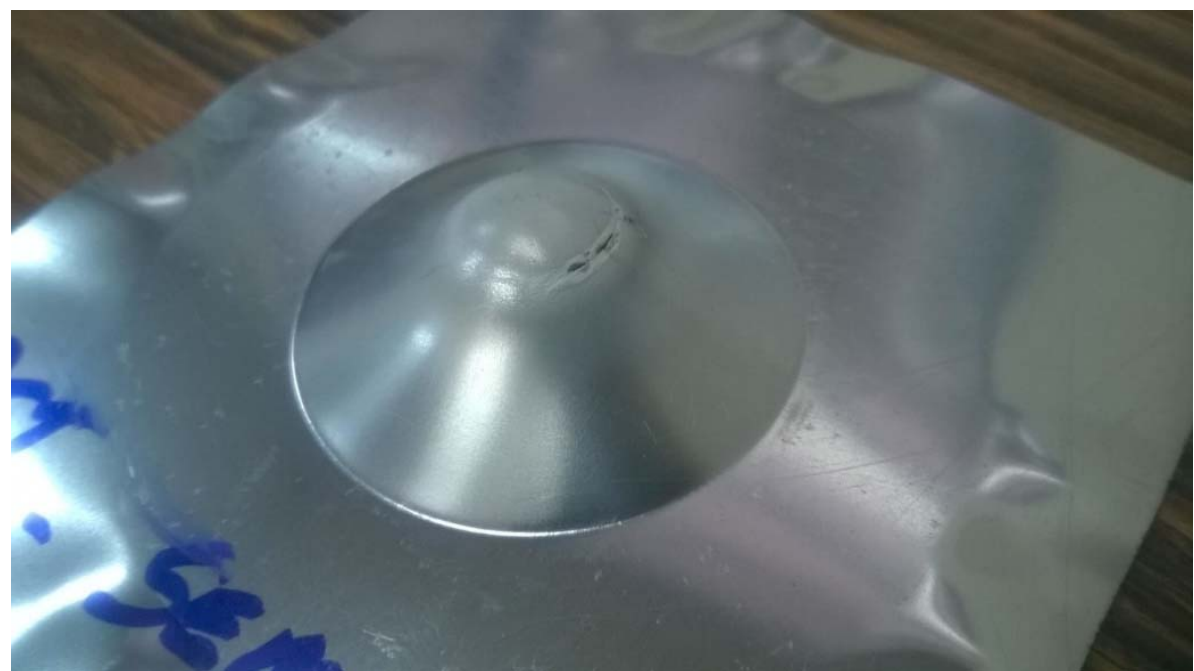

Figura 4. Chapa após o ensaio sem lubrificante. Condição de acabamento 4.

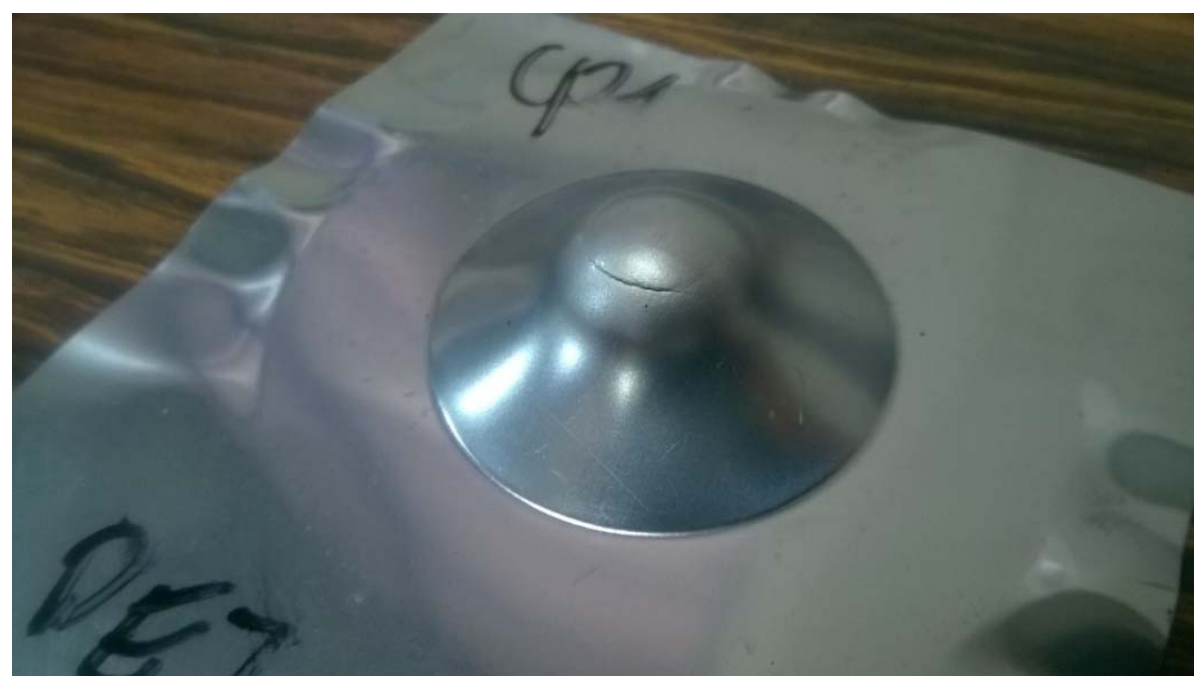

Figura 5. Chapa após o ensaio usando o lubrificante A. Condição de acabamento 4.

\section{CONCLUSÃO}

O presente estudo mostrou a relevância que o regime de lubrificação tem em um processo de estampagem, pois as eficiências foram totalmente distintas entre os quatros sistemas de lubrificação.

Como resultado, o lubrificante $\mathrm{A}$ alcançou o melhor índice de estampabilidade Erichsen, o lubrificante $B$ atingiu um desempenho em média $7,15 \%$ inferior ao lubrificante $\mathrm{A}$, e o lubrificante $\mathrm{C}$ obteve um desempenho oscilatório que acabou por não dar credibilidade ao seu filme lubrificante. Os resultados foram comparados com um sistema sem lubrificação para termos ideia de que a sua não utilização gera um atrito entre a matriz e o punção que acaba por inviabilizar qualquer processo onde seja necessário um acabamento superficial de qualidade, pois foi nítida a melhora do acabamento superficial ao utilizar o lubrificante A.

Deve-se ressaltar que todas as conclusões obtidas são preliminares, já que é um estudo inicial. Esse estudo ainda pode avançar com a alteração na interface de aplicação do lubrificante quando elas são distintas, como no acabamento superficial 3. 


\section{Agradecimentos}

Os autores agradecem à Brasilata S.A. pela Bolsa de Iniciação Científica (Juliano) e pelo material utilizado nos ensaios, no âmbito do projeto "Análise de Materiais e Processos de Soldagem", em parceria com o Laboratório de Soldagem \& Técnicas Conexas da UFRGS.

\section{REFERÊNCIAS}

1 Kobayashi, S.; Oh, S.; Altan.T.; Metal forming and the finite-element method. 1. ed.. New York: Oxford University Press, 1989.

2 Dieter, G,.; Mechanical Metallurgy. 1. ed.. New York: McGraw-Hill Book Company, 1961.

3 Schaeffer, L.; Conformação mecânica. 2. ed.. Porto Alegre: Imprensa Livre, 2004

4 Norma; ISO-20482..Suiça.. Genebra: ISO copyright Office, 2013.

5 Companhia Siderúrgica Nacional. [acesso em 23 mar. 2016]; Disponível em: http://www.csn.com.br/irj/go/km/docs/csn_documentos/CSN/CATALOGO\%20FM.pdf

6 ERICHSEN GmbH \& Co. KG. 2010 [acesso em 10 abril. 2016]; Disponível em: https://www.erichsen.de/service-2/downloads-1/downloads/sheet-metal-testing-201011. 